\title{
Reactions of Grignard Reagents with Nitrous Oxide
}

\author{
Alexander G. Tskhovrebov, Euro Solari, Rosario Scopelliti, and Kay Severin* \\ Institut des Sciences et Ingénierie Chimiques, École Polytechnique Fédérale de Lausanne (EPFL), CH-1015 Lausanne, Switzerland \\ Supporting Information \\ ABSTRACT: The chemical activation of nitrous oxide $\left(\mathrm{N}_{2} \mathrm{O}\right)$ can be achieved by organocalcium, \\ organosodium, and organolithium compounds. Grignard reagents, on the other hand, are believed to be \\ inert. We demonstrate that this generalization is not correct. Some aliphatic Grignard reagents undergo a \\ rapid conversion when subjected to an atmosphere of $\mathrm{N}_{2} \mathrm{O}$. Hydrazones are the main reaction products.

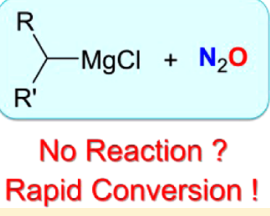

$\mathrm{N}$ itrous oxide is a very inert molecule. Chemical activation under ambient conditions is possible, but highly reactive compounds are typically needed to achieve this goal. ${ }^{1}$ In most cases, these reactions proceed by oxygen atom transfer and liberation of dinitrogen. ${ }^{1,2}$ Examples of reactions in which nitrogen atoms are incorporated into the final product are scarce. The incorporation of intact $\mathrm{N}_{2} \mathrm{O}$ groups was observed for frustrated Lewis pairs, ${ }^{3}$ for N-heterocyclic carbenes, ${ }^{4}$ and for some transition-metal complexes. ${ }^{5,6}$ The utilization of $\mathrm{N}_{2} \mathrm{O}$ as a source of NO ligands has also been reported. ${ }^{7}$ Of industrial importance is the formation of sodium azide from sodium amide and $\mathrm{N}_{2} \mathrm{O} .{ }^{8}$ Organocalcium, ${ }^{9}$ organosodium, ${ }^{10}$ and organolithium compounds ${ }^{11}$ are known to react with $\mathrm{N}_{2} \mathrm{O}$ to give $\mathrm{N}$-containing products. In contrast, organomagnesium compounds are believed to be inert toward $\mathrm{N}_{2} \mathrm{O}$. An early attempt to combine a Grignard reagent with $\mathrm{N}_{2} \mathrm{O}$ was reported by Zerner in $1913 .^{12} \mathrm{He}$ observed that solutions of $\mathrm{MeMgI}$ in diethyl ether did not react with $\mathrm{N}_{2} \mathrm{O}$, even upon heating. The unreactivity of Grignard reagents toward $\mathrm{N}_{2} \mathrm{O}$ was later confirmed by Beringer et al. ${ }^{1 \mathrm{~g}}$ and is now generally accepted knowledge, as evidenced by statements in research reports ${ }^{9}$ and a review article. ${ }^{1 \mathrm{~b}}$ We have recently demonstrated that, in the presence of transition-metal catalysts, Grignard reagents react rapidly with $\mathrm{N}_{2} \mathrm{O}$ to give oxidative $\mathrm{C}-\mathrm{C}$ coupling products. ${ }^{13}$ Control reactions in the absence of metal catalysts showed that phenylmagnesium chloride was indeed very reluctant to react with $\mathrm{N}_{2} \mathrm{O}$, in line with the reports mentioned above. Tests with THF solutions of aliphatic Grignard reagents, however, gave a surprising result: rapid conversion was observed for several compounds. Details about these reactions are reported below.

Subjection of a solution of $i \mathrm{PrMgCl}$ in THF $(2.1 \mathrm{M})$ to an atmosphere of $\mathrm{N}_{2} \mathrm{O}$ resulted in the warming of the reaction mixture along with gas formation. After $1 \mathrm{~h}$, the mixture was quenched with water and analyzed by GC-MS. The data showed that hydrazone 1 had formed in $51 \%$ yield (Scheme 1 ). The reaction was repeated in THF- $d_{8}$. In situ analysis by ${ }^{1} \mathrm{H}$ NMR spectroscopy after $1 \mathrm{~h}$ revealed the formation of propane $(\sim 29 \%)$ along with minor amounts of propene $(<1 \%)$ and some other, unidentified products. Furthermore, the spectrum showed peaks which can be attributed to the deprotonated form of hydrazone 1 (Supporting Information,
Scheme 1. Reaction of $i \mathrm{PrMgCl}$ and $\mathrm{BnMgCl}$ with $\mathrm{N}_{2} \mathrm{O}$

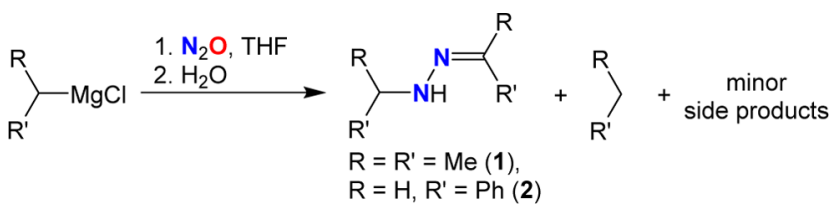

Figure S2). We assume that the rapid transformation of $i \mathrm{PrMgCl}$ into mainly hydrazone and propane is a reflection of its intrinsic reactivity toward $\mathrm{N}_{2} \mathrm{O}$. The participation of trace amounts of transition-metal impurities in the Grignard reagent appears unlikely, because the common $3 \mathrm{~d}$ transition metals lead to oxidative homocoupling as described earlier. ${ }^{13}$

The primary aliphatic Grignard reagent $\mathrm{BnMgCl}$ was found to react with $\mathrm{N}_{2} \mathrm{O}$ in a similar fashion. Addition of $\mathrm{N}_{2} \mathrm{O}$ to a THF solution of $\mathrm{BnMgCl}(2.0 \mathrm{M})$ resulted in the fast formation of hydrazone 2 , which was isolated in $37 \%$ yield in the form of its hydrochloride salt (Scheme 1). ${ }^{14}$ The latter was comprehensively characterized, including a single crystal X-ray analysis (Supporting Information). GC-MS analysis of the reaction mixture revealed the presence of toluene $(44 \%)$ and 1,2-diphenylethane $(18 \%)$ as the main side products.

Hydrazone formation likely proceeds via diazotates (A), obtained by insertion of $\mathrm{N}_{2} \mathrm{O}$ into the $\mathrm{Mg}-\mathrm{C}$ bond (Scheme 2 ). The formation of intermediate diazotates is in line with what has been suggested for $\mathrm{Li}_{-}, \mathrm{Na}-$, and $\mathrm{Ca}$-organic compounds. $^{9-11}$ Deprotonation, cleavage of the $\mathrm{N}-\mathrm{O}$ bond, and coupling with another 1 equiv of $\mathrm{RR}^{\prime} \mathrm{CHMgCl}$ results in

Scheme 2. Proposed Mechanism for the Formation of Hydrazonides by Reaction of Aliphatic Grignard Reagents with $\mathrm{N}_{2} \mathrm{O}$

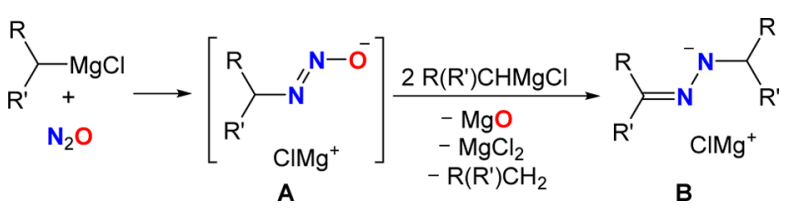

Received: March 31, 2014

Published: May 7, 2014 
the formation of hydrazone anions (B). The order of these processes is presently not clear, but it is conceivable that the reactions involves diazo compounds $R\left(R^{\prime}\right) C_{2}$, which react with $\mathrm{RR}$ 'CHMgCl to give hydrazone anions of type $\mathbf{B} .{ }^{15}$ The proposition that part of the Grignard reagents act as a base is substantiated by the fact that the main side products for the reactions with $i \mathrm{PrMgCl}$ and $\mathrm{BnMgCl}$ are propane and toluene. Evidently, the simple mechanism depicted in Scheme 2 does not reflect the complexity of the real systems, because other side products such as 1,2-diphenylethane are not accounted for. The possibility of concurrent reaction pathways was also proposed for organolithium compounds. ${ }^{1 \mathrm{~b}}$

Another simplification in Scheme 2 is the depiction of the salt byproducts as " $\mathrm{MgO}$ " and " $\mathrm{MgCl}_{2}$ ". These compounds can form solvated magnesium oxohalide clusters. ${ }^{16}$ Evidence for the relevance of such clusters was obtained by X-ray crystallography. Placing a THF solution of $i \mathrm{PrMgCl}$ under an atmosphere of $\mathrm{N}_{2} \mathrm{O}$ and cooling it to $-35{ }^{\circ} \mathrm{C}$ led to the formation of colorless single crystals, which were analyzed by $\mathrm{X}$-ray diffraction. The analysis revealed that the complex $\left[\mathrm{Mg}_{5} \mathrm{Cl}_{4} \mathrm{O}\left(\mathrm{C}_{6} \mathrm{H}_{12} \mathrm{~N}_{2}\right)_{2}(\mathrm{THF})_{5}\right]$ (3) had formed (Figure 1).
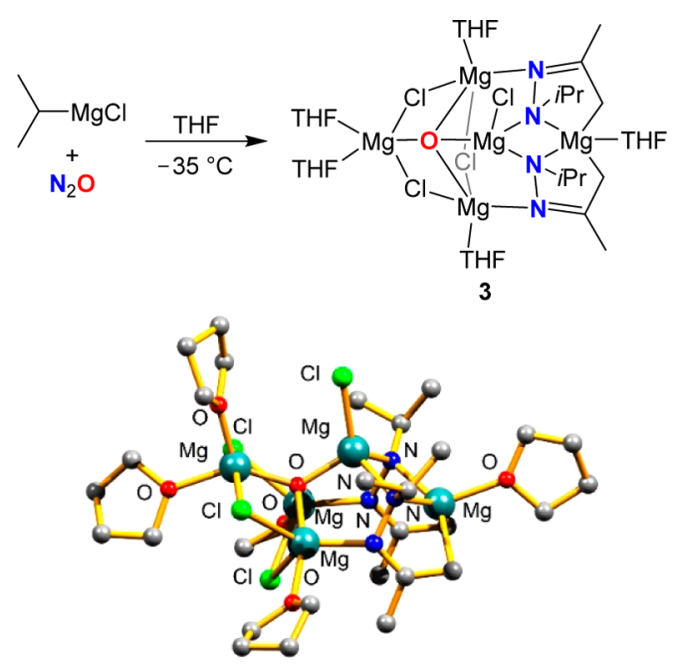

Figure 1. Synthesis of complex 3 and its molecular structure in the crystal. Hydrogen atoms are omitted for clarity.

The pentanuclear cluster features an oxido ligand which is bound to four $\mathrm{Mg}^{2+}$ ions, three bridging and one terminal chlorido ligand, and five THF ligands, as well as two doubly deprotonated hydrazone ligands. Each of these last two ligands is coordinated to three $\mathrm{Mg}^{2+}$ ions via both of its $\mathrm{N}$ atoms $(\mathrm{Mg}-$ $\mathrm{N}=2.0690(15)-2.1777(15) \AA)$ and via one $\mathrm{C}$ atom $(\mathrm{Mg}-\mathrm{C}=$ $2.3487(19) \AA, \quad \mathrm{Mg}-\mathrm{C}^{\prime}=2.4001(18) \AA$ ). A noteworthy structural feature of cluster 5 is the presence of rather long $\mathrm{N}-\mathrm{N}$ bonds (1.4911(18) and 1.4913(19) $\AA$ ). The bond elongation is likely a consequence of the presence of two negative charges on the ligand.

Next, we turned our attention to the simple primary Grignard reagents $\mathrm{EtMgCl}$ and $\mathrm{MeMgI}$. As for $i \mathrm{PrMgCl}$ and $\mathrm{BnMgCl}$, we observed a conversion when the reaction flask was filled with $\mathrm{N}_{2} \mathrm{O}$. The relative reactivity of all four compounds was determined by ${ }^{1} \mathrm{H}$ NMR spectroscopy using THF- $d_{8}$ (all compounds: $0.3 \mathrm{M}, \mathrm{THF})$. The fastest reaction was observed for $\operatorname{EtMgCl}\left(t_{1 / 2} \approx 5 \mathrm{~min}\right)$, followed closely by $i \operatorname{PrMgCl}\left(t_{1 / 2} \approx\right.$ $8 \mathrm{~min})$ and then $\mathrm{BnMgCl}\left(t_{1 / 2}=26 \mathrm{~min}\right)$. The reaction of MeMgI was much slower, with half of the starting material being consumed after $10 \mathrm{~h}$. The observation that the methyl Grignard reagent is the least reactive of all primary Grignard reagents tested is in line with what has been reported for reactions with substrates other than $\mathrm{N}_{2} \mathrm{O} .{ }^{17}$ Still, our results are in apparent contradiction to the reported unreactivity of MeMgI. ${ }^{12}$ However, we were able to confirm that solutions of $\mathrm{MeMgI}$ in diethyl ether are indeed inert toward $\mathrm{N}_{2} \mathrm{O}$ : no noticeable conversion was observed after $24 \mathrm{~h}$ at room temperature. Apparently, the solvent has a pronounced effect on the reactivity. In line with this assumption, we found that the conversion of $\mathrm{BnMgCl}$ was slowed down substantially when the reaction was performed in $\mathrm{Et}_{2} \mathrm{O}$ : upon addition of $\mathrm{N}_{2} \mathrm{O}$, only $28 \%$ conversion of the starting material was observed after $24 \mathrm{~h}$ (THF: $t_{1 / 2}=26 \mathrm{~min}$ ).

Further, we examined the reactivity of a tertiary aliphatic Grignard reagent toward $\mathrm{N}_{2} \mathrm{O}$. The reaction of $t \mathrm{BuMgCl}$ in THF- $d_{8}$ resulted in the formation of 2-methylpropane ( $\left.\sim 43 \%\right)$ and 2-methylpropene ( $\sim 32 \%)$ according to an analysis by ${ }^{1} \mathrm{H}$ NMR spectroscopy after $15 \mathrm{~h}$. The formation of $\mathrm{N}$ containing products was not observed in this case.

Having established that primary and secondary aliphatic Grignard reagents are suited reagents for reactions with $\mathrm{N}_{2} \mathrm{O}$, we have investigated whether we could use this transformation for synthetic purposes. Aliphatic hydrazones are very sensitive compounds which decompose rapidly. ${ }^{18,19}$ Therefore, we decided to target the hydrolysis products by adding an acidic workup step. Using this procedure, it was possible to convert $i \mathrm{PrMgCl}$ into the corresponding hydrazinium salt ( $i \mathrm{Pr}-$ $\mathrm{NH}_{2} \mathrm{NH}_{2}$ ) $\mathrm{Cl}$ (4) in $44 \%$ yield (Scheme 3 ). The Grignard reagents $\mathrm{CyMgCl}, \mathrm{EtrMgCl}$, and $\mathrm{Ph}\left(\mathrm{CH}_{2}\right)_{2} \mathrm{MgCl}$ react in a related fashion, and we were able to isolate the salts 5-7 with yields between 42 and 63\% (Scheme 3).

Scheme 3. Reactions of Aliphatic Grignard Reagents with $\mathrm{N}_{2} \mathrm{O}^{a}$

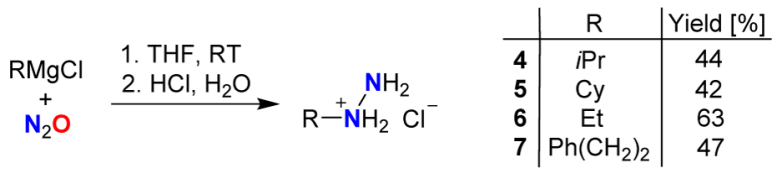

${ }^{a_{T}}$ The yields are calculated on the basis of the assumption that 2 equiv of $\mathrm{RMgCl}$ is needed to generate the hydrazinium salts.

The atom economy of this process is not very good. Part of the $\mathrm{RMgCl}$ starting material is lost during the reaction with $\mathrm{N}_{2} \mathrm{O}$ in the form of $\mathrm{RH}$, and the hydrolytic workup results in further loss of material. However, this new reaction allows the conversion of Grignard reagents in a straightforward fashion into hydrazines. One should also note that the standard procedure for synthesizing hydrazines (reductive amination of a carbonyl compound with Boc-protected hydrazine, followed by deprotection $)^{20}$ is not very atom economical either. The formation of alkylhydrazines by reaction of hydrazine with alkyl halides is known, but it is not often used for the synthesis of monoalkylhydrazines because of problems with overalkylation. $^{21}$

To conclude: for about a century, Grignard reagents have been believed to be inert toward $\mathrm{N}_{2} \mathrm{O}$. We show that this generalization is not correct. While some organomagnesium compounds are in fact rather reluctant to react with $\mathrm{N}_{2} \mathrm{O}$, there are others which react within minutes at ambient temperature. In particular, THF solutions of primary (with the exception of 
$\mathrm{MeMgI}$ ) and secondary aliphatic Grignard reagents undergo a rapid conversion when subjected to an atmosphere of $\mathrm{N}_{2} \mathrm{O}$. As the main reaction products, we have identified hydrazones and alkanes derived from protonation of $\mathrm{RMgX}$. When the reaction of Grignard reagents with $\mathrm{N}_{2} \mathrm{O}$ is combined with an acidic workup, it is possible to obtain alkylhydrazinium salts on a preparative scale. These conversions are rare examples of reactions in which $\mathrm{N}_{2} \mathrm{O}$ is used as an $\mathrm{N}$-donor in synthetic organic chemistry.

\section{ASSOCIATED CONTENT}

\section{S Supporting Information}

Text, figures, a table, and CIF files giving experimental details and characterization data for the compounds prepared in this paper and crystallographic data for $\mathbf{1}+\mathbf{1} \cdot \mathbf{0 2} 2,2$, and 3 . This material is available free of charge via the Internet at http:// pubs.acs.org.

\section{AUTHOR INFORMATION}

\section{Corresponding Author}

*E-mail for K.S.: kay.severin@epfl.ch.

\section{Notes}

The authors declare no competing financial interest.

\section{ACKNOWLEDGMENTS}

The work was supported by the Ecole Polytechnique Fédérale de Lausanne (EPFL) and the Swiss National Science Foundation. A.G.T. thanks Dr. Pascal Mieville for support with NMR measurements.

\section{REFERENCES}

(1) Reviews: (a) Tolman, W. B. Angew. Chem., Int. Ed. 2010, 49, 1018-1024. (b) Leont'ev, A. V.; Fomicheva, O. A.; Proskurnina, M. V.; Zefirov, N. S. Russ. Chem. Rev. 2001, 70, 91-104.

(2) For examples see: (a) Franke, S. M.; Tran, B. L.; Heinemann, F. W.; Hieringer, W.; Mindiola, D. J.; Meyer, K. Inorg. Chem. 2013, 52, 10522-10588. (b) Tskhovrebov, A. G.; Solari, E.; Scopelliti, R.; Severin, K. Organometallics 2012, 31, 7235-7240. (c) Horn, B.; Limberg, C.; Herwig, C.; Feist, M.; Mebs, S. Chem. Commun. 2012, 48, 8243-8345. (d) Yonke, B. L.; Reeds, J. P.; Zavalij, P. Y.; Sita, L. R. Angew. Chem., Int. Ed. 2011, 50, 12342-12346. (e) Wang, Z.-C.; Dietl, N.; Kretschmer, R.; Weiske, T.; Schlangen, M.; Schwarz, H. Angew. Chem., Int. Ed. 2011, 50, 12351-12354. (f) Harrold, N. D.; Waterman, R.; Hillhouse, G. L.; Cundari, T. R. J. Am. Chem. Soc. 2009, 131, 12872-12873. (g) Figueroa, J. S.; Cummins, C. C. J. Am. Chem. Soc. 2003, 125, 4042-4021. (h) Kaplan, A. W.; Bergman, R. G. Organometallics 1998, 17, 5072-5085. (i) Groves, J. T.; Roman, J. S. J. Am. Chem. Soc. 1995, 117, 5594-5595. (j) Koo, K.; Hillhouse, G. L.; Rheingold, A. L. Organometallics 1995, 14, 456-460. (k) Cummins, C. C.; Schrock, R. R.; Davis, W. M. Inorg. Chem. 1994, 33, 1448-1457. (1) Matsunaga, P. T.; Hillhouse, G. L.; Rheingold, A. L. J. Am. Chem. Soc. 1993, 115, 2075-2077. (m) Bottomley, F.; Magill, C. P.; Zhao, B. Organometallics 1991, 10, 1946-1954.

(3) (a) Kelly, M. J.; Gilbert, J.; Tirfoin, R.; Alridge, S. Angew. Chem., Int. Ed. 2013, 52, 14094-14097. (b) Ménard, G.; Hatnean, J. A.; Cowley, H. J.; Lough, A. J.; Rawson, J. M.; Stephan, D. W. J. Am. Chem. Soc. 2013, 135, 6446-6449. (c) Neu, R. C.; Otten, E.; Lough, A.; Stephan, D. W. Chem. Sci. 2011, 2, 170-176. (d) Neu, R. C.; Otten, E.; Stephan, D. W. Angew. Chem., Int. Ed. 2009, 48, 9709-9712. (e) Otten, E.; Neu, R. C.; Stephan, D. W. J. Am. Chem. Soc. 2009, 131, 9918-9919.

(4) (a) Theuergarten, E.; Bannenberg, T.; Walter, M. D.; Holschumacher, D.; Freytag, M.; Daniliuc, C. G.; Jones, P. G.; Tamm, M. Dalton Trans. 2014, 43, 1651-1662. (b) Göhner, M.; Haiss, P.; Kuhn, N.; Stöbele, M.; Zeller, K.-P. Z. Naturforsch., B 2013, 68b, 539-545. (c) Tskhovrebov, A. G.; Vuichod, B.; Solari, E.; Scopelliti, R.; Severin, K. J. Am. Chem. Soc. 2013, 135, 9486-9492. (d) Tskhovrebov, A. G.; Solari, E.; Wodrich, M. D.; Scopelliti, R.; Severin, K. J. Am. Chem. Soc. 2012, 134, 1471-1473. (e) Tskhovrebov, A. G.; Solari, E.; Wodrich, M. D.; Scopelliti, R.; Severin, K. Angew. Chem., Int. Ed. 2012, 51, 232-234.

(5) (a) Pomowski, A.; Zumft, W. G.; Kroneck, P. M. H.; Einsle, O. Nature 2011, 477, 234-237. (b) Piro, N. A.; Lichterman, M. F.; Harman, W. H.; Chang, C. J. J. Am. Chem. Soc. 2011, 133, 2108-2111. (c) Paulat, F.; Kuschel, T.; Näther, C.; Praneeth, V. K. K.; Sander, O.; Lehnert, N. Inorg. Chem. 2004, 43, 6979-6994. (d) Pamplin, C. B.; Ma, E. S. F.; Safari, N.; Rettig, S. J.; James, B. R. J. Am. Chem. Soc. 2001, 123, 8596-8597. (e) Bottomley, F.; Brooks, W. V. F. Inorg. Chem. 1977, 16, 501-502. (f) Bottomly, F.; Crawford, J. R. J. Am. Chem. Soc. 1972, 94, 9092-9095. (g) Armor, J. N.; Taube, H. Chem. Commun. 1971, 287-288. (h) Armor, J. N.; Taube, H. J. Am. Chem. Soc. 1969, 91, 6874-6876.

(6) Demir, S.; Montalvo, E.; Ziller, J. W.; Meyer, G.; Evans, W. J. Organometallics 2010, 29, 6608-6611. (b) Laban, T.; Mandel, A.; Magull, J. Z. Anorg. Allg. Chem. 1999, 625, 1273-1277. (c) Vaughan, G. A.; Sofield, C. D.; Hillhouse, G. L. J. Am. Chem. Soc. 1989, 111, 5491-5493.

(7) (a) Cavigliasso, G.; Criddle, A.; Kim, H.-S.; Stranger, R.; Yates, B. F. Dalton Trans. 2014, 43, 4631-4634. (b) Tskhovrebov, A. G.; Solari, E.; Scopelliti, R.; Severin, K. Inorg. Chem. 2013, 52, 11688-11690. (c) Reeds, J. O.; Yonke, B. L.; Zavalij, P. Y.; Sita, L. R. J. Am. Chem. Soc. 2011, 133, 18602-18605. (d) Cherry, J.-P. F.; Johnson, A. R.; Baraldo, L. M.; Tsai, Y.-C.; Cummins, C. C.; Kryatov, S. V.; RybakAkimova, E. V.; Capps, K. B.; Hoff, C. D.; Haar, C. M.; Nolan, S. P. J. Am. Chem. Soc. 2001, 123, 7271-7286. (e) Johnson, A. R; Davis, W. M.; Cummins, C. C.; Serron, S.; Nolan, S. P.; Musaev, D. G.; Morokuma, K. J. Am. Chem. Soc. 1998, 120, 2071-2085. (f) Laplaza, C. E.; Odom, A. L.; Davis, W. M.; Cummins, C. C. J. Am. Chem. Soc. 1995, 117, 4999-5000.

(8) Haase, J. In Organic Azides: Syntheses and Applications; Bräse, S., Banert, K., Eds.; Wiley-VCH: Weinheim, Germany, 2010; p 30.

(9) (a) Hays, M.; Hanusa, T. P. Tetrahedron Lett. 1995, 36, 24352436. (b) Meier, R.; Rappold, K. Angew. Chem. 1953, 65, 560-561.

(10) Schlenk, W.; Bergmann, E. Justus Liebigs Ann. Chem. 1928, 464, $1-21$.

(11) (a) Kurusawa, M.; Nankawa, T.; Matsuda, T.; Kubo, K.; Kurihara, M.; Nishihara, H. Inorg. Chem. 1999, 38, 5113-5123. (b) Nesmeyanov, A. N.; Perevalova, E. G.; Nikitina, T. V. Dokl. Akad. Nauk SSSR 1961, 138, 1118-1121. (c) Müller, E.; Rundel, W. Chem. Ber. 1957, 90, 1302-1306. (d) Meier, R.; Frank, W. Chem. Ber. 1956, 89, 2747-2750. (e) Müller, E.; Ludsteck, D.; Rundel, W. Angew. Chem. 1955, 67, 617. (f) Meier, R. Chem. Ber. 1953, 86, 1483-1492. (g) Beringer, F. M.; Farr, J. A., Jr.; Sands, S. J. Am. Chem. Soc. 1953, 75, 3984-3987.

(12) Zerner, E. Monatsh. Chem. 1913, 34, 1609-1631.

(13) Kiefer, G.; Jeanbourquin, L.; Severin, K. Angew. Chem., Int. Ed. 2013, 52, 6302-6305.

(14) The sensitivity of the neutral hydrazone 2 prevented its isolation in pure form. We were therefore not able to obtain a calibration curve for the GC-MS measurements. A value for the crude yield of $\mathbf{2}$ is thus not given.

(15) For reactions of Grignard reagents with diazo compounds see: (a) Ciganek, E., Electrophilic Amination of Carbanions, Enolates, and Their Surrogates. In Organic Reactions; Wiley: Hoboken, NJ, 2004; Vol. 72, p 16. (b) Severin, T.; Pehr, H. Chem. Ber. 1979, 112, 35593565. (c) Huisgen, R. Angew. Chem. 1955, 67, 439-463.

(16) (a) Vitze, H.; Lerner, H.-W.; Bolte, M. Acta Crystallogr., Sect. E 2011, E67, m1614. (b) Stucky, G.; Rundle, R. E. J. Am. Chem. Soc. 1964, 86, 4821-4825.

(17) (a) Blomberg, C. In Handbook of Grignard Reagents; Silverman, G. S., Rakita, P. E., Eds.; Marcel Dekker: New York, 1996; p 249-268 and references therein. (b) Holm, T. Acta Chem. Scand. 1988, B42, 685-689. (c) Ivanoff, D.; Spasoff, A. Bull. Soc. Chim. Fr. Ser. IV 1932, 51,619 . 
(18) For the autooxidation of hydrozones to hydrazone radicals, see: Harej, M.; Dolenc, D. J. Org. Chem. 2007, 72, 7214-7221 and references therein.

(19) Storage of hydrazone $\mathbf{1}$ at $-35^{\circ} \mathrm{C}$ in air for 2 weeks led to the formation of crystals of the corresponding azohydroperoxide $\left(\mathbf{1} \cdot \mathbf{O}_{2}\right)$, which was characterized by X-ray diffraction (see the Supporting Information).

(20) (a) Connolly, T. J.; Crittall, A. J.; Ebrahim, A. S.; Ji, G. Org. Process Res. Dev. 2000, 4, 526-529. (b) Ghali, N. I.; Venton, D. L.; Hung, S. C.; Le Breton, G. C. J. Org. Chem. 1981, 46, 5413-5414.

(21) (a) Hydrazine. In Ullmann's Encyclopedia of Industrial Chemistry; VCH: Weinheim, Germany, 2012; Vol. 18, p 92. (b) Kost, A. N.; Sagitullin, R. S. Russ. Chem. Rev. 1964, 33, 159-176. 